\title{
EXTINCTION AND SYNESTHESIA IN PATIENTS WITH SPINAL CORD INJURIES
}

\author{
By ERNEST Bors, M.D. \\ Southwest Regional System for Treatment of Spinal Cord Injury, \\ Good Samaritan Hospital, Phoenix, Arizona, U.S.A.
}

Abstract. Extinction and synesthesia were studied in 50 patients with spinal cord injury with various levels and extents. Extinction was found in 20 (40 per cent) and synesthesia in 6 ( 12 per cent) of the 40 males and Io females. No correlations were found between either of the two phenomena and parameters of patient's age, lesion's age, lesion's level and extent, or accompanying head injury. The latter occurred in 22/50 patients (44 per cent), diagnosed by a history of amnesia.

Extinction was tested by synchronous double stimulation unilaterally and bilaterally, symmetrically and asymmetrically. It was more frequent unilaterally than bilaterally. The modalities of superficial sensibility were prone to be extinct but those of deep sensibility (pallesthesia from bone conduction and kinesthesia) were not. Extinction of tactile responses did not imply that all other skin modalities (pain, temperature, pressure, skin pallesthesia) will also be extinct in an all or nothing fashion. Modalities could become extinct either singly or in combination. Extinction in spinal man was presumed to be caused by a reduction of perception in hypesthetic areas and was of diagnostic value insofar as its segmental distribution suggested the longitudinal extent of a cord lesion. This concept is in accord with the results of monkey experiments by Eidelberg and Schwartz (I97I).

Synesthesia in spinal man is not identical with synchiria of the monkey. It is not in a reciprocal relationship with extinction and both phenomena co-existed in four of the six patients. Synesthesia is elicited by a stimulus delivered to the normesthetic skin above the level of the lesion with two responses: one well localised at the site of stimulation and the other unilaterally or bilaterally in anaesthetic parts of the body. Five of the six patients reported volitional phantom movements of somatic (toes) and/or visceral (micturition-defaecation) structures. Such sensations are elicited by remembering the engrams of pre-traumatic experiences in areas of the body image connected with motor function. Synesthesia could be understood as a sensory counterpart in areas of the body image when ascending impulses of actual perception are mixed with impulses modulated at the artificial synapse of the rostral cord stump creating a phantom sensation.

Key words: Synesthesia; Spinal cord injury; Extinction phenomena.

\section{Introduction}

THE following report on the phenomena of extinction and synesthesia in spinal man is dedicated to Sir Ludwig Guttmann with affectionate respect and every good wish on his birthday. While I am aware that I have transgressed the territorial boundaries of my urological specialty, I also believe that Sir Ludwig will understand and condone my action for the following reasons:

Sir Ludwig and I hail from a generation of physicians and surgeons prior to the specialisation and subspecialisation of today. As M.D.s we were permitted to focus our interest on any facet of medicine and/or surgery as long as we adhered to the principles of 'primum non nocere' and of 'observe and think', preached to us by our 
teachers, and as long as we remained aware of our limitations by judging what we could and what we could not achieve.

The management and investigation of spinal man have emerged during the past 30 years as a specialty, thanks to a man like Sir Ludwig. This special field is recognised as such in the United Kingdom and in some 46 countries where British Medicine is influential (Guttmann, 1976). A similar attitude has developed in the United States since World War II, and serious efforts are in progress and promising to establish a Specialty Board of Spinal Cord Injury.

Sir Ludwig's monumental book (1976) attests to his 'Credo' of a holistic approach to the multidisciplinary problems of spinal man which cross many departmental boundaries and allow the respective physician to treat the various aspects of this condition. This does not exclude that specialists from different fields will be consulted upon the discretion of the 'paraplegia specialist' without fragmentation of the patient's management.

With this philosophy in mind I have studied the 50 patients presented here. Everyone who spends time enough taking the history and examining a patient has encountered 'bizarre' reports and findings in the sensory experience ranging from phantom sensations to synesthesia and extinction. Extinction has been studied in the past in patients with cerebral lesions clinically and in primates experimentally (for references, viz. Schwartz et al., 1977), but only Bender (1945, 1952) has mentioned also patients with spinal cord lesions. In the following I have tried to understand the phenomena of extinction and synesthesia in patients with spinal cord trauma.

\section{Patients and Methods}

Fifty patients with traumatic spinal cord lesions were examined at random, 40 males and ro females.

After taking the history with special attention to amnesia, a motor and sensory evaluation was done. A worksheet is shown in Figure I. Touch was tested by means of a wisp of tissue paper, vibration with a tuning fork $258 \mathrm{C}$, superficial pain was elicited by an algometer at $\mathrm{I} 5$ to $75 \mathrm{~g}$ load and deep pain by manual pressure to finger-and toes tips, the Achilles tendons and testicles. Temperature perception was elicted by Minnesota discs (Dyck et al., 1974). Abdominal lateralisation and localisation were assessed by mild finger pressure to the following six points: substernal notch, aortic notch between umbilicus and xyphoid process, bilateral epigastrium above the umbilicus, bilateral hypogastrium below the umbilicus, and suprapubic notch.

The autonomic deficit was examined for sweating (Spoon test, Bors, I964), dermographism and by palpation of the skin texture.

When only one stimulus was applied it was done in the customary direction caudo-cephalad on each side of the body.

When two stimuli were used either unilaterally or bilaterally to homologous or non-homologous areas, that was done simultaneously lest false responses might be caused through changes of attention.

Bender's (I952) definitions were used for 'extinction' and 'synesthesia'. In extinction two stimuli are applied causing one 'well localised' sensation but 'the other is poorly perceived or not at all'. In synesthesia (or synchiria) one stimulus will cause 'two sensations of which one is well localised' while 'the other appears in an area in which there is dysesthesia or burning pain or on the opposite side of the body'. In the patients with synesthesia the stimulus was applied to an area above the cord lesion. 
FIG. I

Sensory

$\begin{array}{llll}\begin{array}{c}\text { Unilat. } \\ \text { I stimul. }\end{array} & \begin{array}{c}\text { Unilat. } \\ \text { 2 stimul. }\end{array} & \begin{array}{c}\text { Bilat. } \\ \text { 2 stimul. } \\ \text { (homologous) }\end{array} & \begin{array}{c}\text { Bilat. } \\ \text { stimul. } \\ \text { (non-homologous) }\end{array} \\ \quad \mathrm{R} & \frac{\mathrm{R}}{\mathrm{L}} \mathrm{R}\end{array}$

A. Touch

B. Vibration:

a. skin

b. bone

C. Pain:
a. pain
b. deep pressure
Finger Toe
Achilles
Testes

D. Minnesota temperature disks

E. Kinesthesia

F. Abdominal

laterisation and localisation

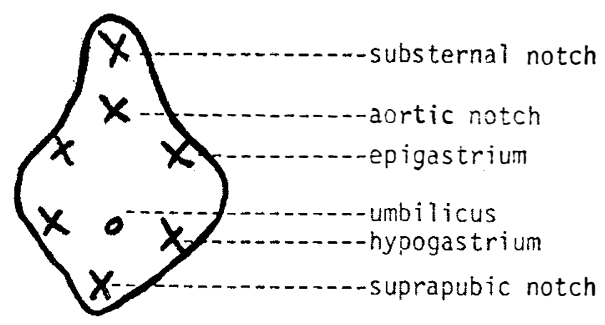

G. Autonomic deficit:

a. spoon test.

b. dermographism.

c. skin texture.

Based upon the presence or absence of extinction with or without synesthesia or the rare presence of synesthesia without extinction, the original two groups of 40 male and Io female patients were further subdivided into four groups: Group I2I males without either extinction or synesthesia, Group II-I9 males with either extinction or synesthesia or both, Group III-seven females without either extinction or synesthesia, Group IV-three females with either synesthesia alone in one or extinction alone in two patients.

These four groups of patients were studied in regard to various parameters, such as ages of patients and lesions, respectively, level and extent of lesion and the presence or absence of amnesia.

Age of Patient

\section{Observations}

Age ranged from I4-59 years in Group I (2I males), from I7-5I years in Group II (I9 males), from I6-4I years in Group III (seven females), and from 
TABLE I

Age of patient

\begin{tabular}{ccccc}
\hline & \multicolumn{2}{c}{ Males } & \multicolumn{2}{c}{ Females } \\
\cline { 2 - 5 } Group & I & II & III & IV \\
\hline II-20 & 2 & 2 & 5 & 2 \\
2 II-30 & 8 & 7 & I & 0 \\
3 II-40 & 0 & 4 & I & 0 \\
4 I-50 & 6 & 5 & 0 & 0 \\
5 I-60 & 5 & I & 0 & I \\
& - & - & - & - \\
& 2 I & I9 & 7 & 3 \\
\hline
\end{tabular}

TABLE II

Age of injury

\begin{tabular}{|c|c|c|c|c|}
\hline Group & I & II & III & IV \\
\hline Up to I mo. & 2 & I & I & 0 \\
\hline I-2 mos. & 3 & 2 & I & I \\
\hline 3-6 mos. & 2 & 2 & I & 0 \\
\hline 7-12 mos. & I & 2 & I & 0 \\
\hline I-2 yrs. & 2 & 2 & I & I \\
\hline Up to 3 yrs. & 5 & 2 & I & c \\
\hline Up to 4 yrs. & 2 & 4 & o & c \\
\hline Up to 5 yrs. & I & 0 & o & $c$ \\
\hline Up to 6 yrs. & I & 0 & 0 & c \\
\hline Up to 7 yrs. & 0 & 0 & 0 & 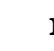 \\
\hline Up to 8 yrs. & I & I & 0 & 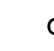 \\
\hline Up to 9 yrs. & o & 2 & 0 & 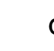 \\
\hline Up to Io yrs. & 0 & 0 & 0 & $c$ \\
\hline \multirow[t]{3}{*}{ IO + yrs. } & $\mathbf{I}$ & I & I & $c$ \\
\hline & - & 一 & - & - \\
\hline & $2 \mathrm{I}$ & I9 & 7 & 3 \\
\hline
\end{tabular}

TABLE III

Level and Extents of Lesions

\begin{tabular}{lcrrr}
\hline $\begin{array}{c}\text { Group I } \\
\text { (Male) }\end{array}$ & $\begin{array}{c}\text { Group II } \\
\text { (Male) }\end{array}$ & $\begin{array}{c}\text { Group III } \\
\text { (Female) }\end{array}$ & $\begin{array}{c}\text { Group IV } \\
\text { (Female) }\end{array}$ \\
\hline CI: 4 & CI: 3 & CC: 2 & CC: I \\
CC: 6 & CC: 4 & TC: 5 & TI: I \\
TI: I & TI: 2 & - & TC: I \\
TC: 8 & TC: 6 & 7 & - \\
LI: I & LI: 0 & & 3 \\
LC: I & LC: 4 & & & \\
- & & & & \\
2I & I9 & & \\
\hline
\end{tabular}

CI: cervical incomplete. CC: cervical complete. TI: thoracic incomplete. TC: thoracic complete. LI: lumbar incomplete. LC: lumbar complete. 
I7-52 years in Group IV (three females). Table I shows age distribution by decades.

Age of Injury

Age of injury ranged from 0.5-I25 months in Group I (2I pts.), from 0.5-I2I months in Group II (I9 pts.), from 0.5-132 months in Group III (7 pts.), and from 2-73 months in Group IV. Table II shows age distribution of the lesion by months and years.

\section{Level and Extents of Lesions}

Level and extents of lesions are shown in Table III. If one combines the non-affected Groups I and III and the affected Groups II and IV, together one arrives at the following distribution:

$\begin{array}{llrllr}\text { Groups I and III } & \text { CI } & 4 & \text { Groups II and IV } & \text { CI } & 3 \\ & \text { CC } & 8 & \text { CC } & 5 \\ \text { TI I } & \text { TI } 3 \\ \text { TC I3 } & \text { TC } \\ \text { LI I } & \text { LI } 0 \\ \text { LC I } & \text { IC } & 4 \\ & & & \\ 28 & & \end{array}$

\section{Incidence of Amnesia}

Amnesia was present in Io of 2 I patients of Group I, in 8 of I9 in Group II, in 3 of 7 in Group III and in I of 3 patients in Group IV. Twentytwo of the 50 patients reported amnesia; it occurred in $13 / 28$ patients without extinction or synesthesia and in 9/22 patients with either extinction or synesthesia or both.

\section{Extinction}

Extinction was observed in I8/19 patients in Group II and in 2/3 patients in Group IV, i.e., in a total of $20 / 50$ patients.

In Group II most frequently extinct was light touch ( 9 pts.), then followed pain (8 pts.), pallesthesia from the skin ( 5 pts.) and thermesthesia (4 pts.). One modality ${ }^{1}$ only was extinct in I I patients, while two modalities were extinct in five patients and in two patients extinction of three modalities occurred. No extinction of pallesthesia by bone conduction or of kinesthesia was observed.

The lesion's level was cervical in six, thoracic in seven and lumbar in five patients. The lesions were considered to be complete in 14 , and incomplete in four patients.

In the majority extinction was confined to one (I I pts.) or two ( 5 pts.) segments below normesthesia, only in two patients did it exceed two segments.

\section{Laterality}

Exclusively unilateral responses obtained in I I patients, unilateral and bilateral homologous in two patients, unilateral and bilateral non-homologous in three

${ }^{1}$ Calne and Pallis (I966) have taken issue with the term 'modality' which 'is ambiguous'. I use it for clinical practical reasons to denote what somesthetic experience can be elicited by different stimuli without implying specificity of receptors, tracts and terminals. 
patients and unilateral and bilateral homologous and non-homologous responses were present in two patients.

In Group IV extinction was present in two/three patients. Touch and pain were extinct in one patient and pain and skin pallesthesia in the other.

A C 5 complete injury was found in one and an incomplete lesion below $\mathrm{T}_{\mathrm{I}} 2$ in the other patient.

Extinction extended to two segments, in one (C5C) patient, in the other it exceeded two segments.

One patient had only a unilateral, the other a unilateral and bilateral nonhomologous response.

In summing up the observations in 20 patients of Groups II and IV it was found that the modality of touch was extinct in ten patients, of pain in ten patients, of skin pallesthesia in six patients and of thermesthesia in four patients. One modality only was extinct in I I patients, two modalities in seven patients and three modalities in two patients.

The level was cervical in seven patients, thoracic in eight patients and lumbar in five patients. The lesions were considered to be complete in 15 patients and incomplete in five patients.

Extinction extended only to one segment in I I patients, to two segments in six patients and to more than two segments in three patients.

\section{Synesthesia}

This was observed in five patients of Group II and in one patient of Group IV, i.e., it occurred in 6/50 patients. In Group II synesthesia without extinction was noted in one patient and the same was true of the only patient with synesthesia in Group IV.

Synesthesia of Group II was present in one patient with a complete cervical lesion, in another with a complete thoracic lesion, in two patients with incomplete cervical lesions and one patient with a complete lumbar lesion. Synesthesia in Group IV concerned a patient with a complete thoracic lesion.

In the following the highlights of each patient with synesthesia are reported:

I. L.S., male, 25 years, tetraplegia of more than ro years' duration with a complete lesion below $\mathrm{C}_{5}$. Touch, pressure or vibration applied to $\mathrm{C}_{3}$ will cause a radiating sensation to the ipsilateral shoulder and elbow. Sphincter phantom with voluntary phantom movement. Defaecation phantom stronger than micturition phantom

2. C.B., male, 33 years, paraplegia of $\mathrm{I} \frac{1}{2}$ years' duration with a complete lesion below T9. When he scratches the skin of the upper thoracic segments he feels a quick twinge of pain in the ipsilateral groin. But that occurs only occasionally and cannot be demonstrated upon 'command.' Phantom of desire of defaecation. No voluntary or involuntary phantom movements in extremities.

3. J. S., male, 3 I years, paraplegia of slightly over 3 years' duration with a complete lesion below L 4 on the left and LI on the right. During the last $I_{2} \frac{1}{2}$ years, he observed that stimulation of an area of normal perception will cause a response in anaesthetic areas. Scratching the sternum causes a sensation in the perineum. Objectively: pressure to T8-T I0 causes ipsilateral responses in lumbar segments L2-3. Light touch or pressure to the costovertebral angle will elicit a response in two ipsilateral areas: $(a)$ at the bottom of the sole near the heel and $(b)$ at the outer aspect of the lower leg and the fibular head, as if somebody would rub that area with rough material. Volitional phantom movements in toes. Micturition phantom. 
4. O.M., male, 32 years, tetraplegia of 9 years' duration with an incomplete

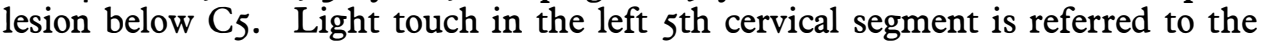
ipsilateral thoracic segments $(\mathrm{I}-7)$. Stimulating the right $\mathrm{C}_{5}$ area is referred to the ipsilateral right leg corresponding to about L2. Volitional phantom movements in toes and sphincter.

5. T.B., male, 2 I years, tetraplegia of $3 \frac{1}{4}$ years' duration with an incomplete lesion below $\mathrm{C}_{5}$ suggestive of an anterior cord syndrome. Stimulation by touch to the left TII segment causes a sensation in the anterior aspect of the ipsilateral thigh. Volitional phantom movements of toes. Defaecation phantom, urination phantom (of short duration).

6. A.W., female, 52 years, paraplegia of 6 years' duration with a complete lesion below T6. When rubbing the segments $\mathrm{T} 4$ to $\mathrm{T} 6$ in order to relieve pain in the right ribs she experiences a 'deep sensation' in both legs (ipsi- and contralaterally) which is not disagreeable but she rather 'likes it'. That sensation can be also elicited from stimulating the skin at the fracture site on her back. The same response can be elicited by using light touch, pressure or vibration as a stimulus. Toe and sphincter phantoms, defaecation and micturition phantoms.

Two of the six patients showed no extinction, namely one male $\left(\mathrm{C}_{5} \mathrm{C}\right)$ and the one female (T6C) patient.

\section{Extinction}

\section{Discussion}

Bender (1948, I952) and Critchley (1949, I953) reviewed the history of simultaneous double stimulation which was introduced by Oppenheim (1885). Bender (1948) and Critchley (1949) also reported the synonyms of tactile extinction or tactile inattention, respectively, such as sensory suppression and sensory eclipse. Most neurologists were interested in laterality, 'testing the two sides of the body simultaneously was required in order to discover this suppression' (Nathan, I946) caused by cortical damage of the parietal lobe although fronto-parietal, temporoparietal or occipito-parietal areas were involved in some instances. While Bender (1945, I948 and 1952) realised that extinction results most often from brain damage, he was the first to draw attention to patients with spinal cord lesions of traumatic (Brown-Séquard) and non-traumatic (cord tumor) origin. He pointed out how useful the ipsilateral simultaneous double stimulation was in determining the borders of the lesion. While he mentioned a 'series', of patients with cervical Brown-Séquard syndromes, without giving their numbers nor quoting the incidence of extinction, he described in detail one patient with a traumatic BrownSéquard lesion and two patients with cord tumours (Bender, 1945, I948 and 1952).

Among the 50 patients presented here, 20 (40 per cent) showed extinction for one or more modalities of superficial but none of deep sensibility of pallesthesia (by bone conduction) or kinesthesia. Responses occasionally differed comparing one side with the other but were never extinct. Bender (1945) observed that vibration sense was least vulnerable.

Contrary to Wortis et al. (I948) that all cutaneous modalities act as one unit when extinct we found that light touch and pin prick were extinct in ten instances each, then followed skin pallanesthesia (six instances) and finally thermanesthesia (four instances). One modality by itself was extinct in I I patients and two or more combined skin modalities were extinct in nine patients. In no instance did the age of the patient, or of the lesion, the level and extent of the lesion seem to play a role. I cannot explain the discrepancy between the findings of Wortis et al. (I948) and 
those presented here. Also unexplained remain the facts that an exclusive ipsilateral response obtained in 12 patients while a combination of ipsi- and contralateral responses, in symmetrical or asymmetrical areas, was found in eight patients.

Extinction involved one segment in a majority of I I patients, in six patients it included two segments and in three patients it extended over more than two segments. These findings would suggest the longitudinal extension of the lesion.

Inasmuch as the phenomenon of extinction is most frequently caused by cortical cerebral lesions, the history of amnesia was recorded as a sign of head injury. It was present in 22 of 50 patients (44 per cent). Comparing patients with amnesia and extinction or synesthesia or both (9/22 patients), with those with anamnesia but without extinction or synesthesia (I3/28) showed a percentage of $4 \mathrm{I}$ per cent $v .46$ per cent. This does suggest that head injury is not the cause of extinction or synesthesia.

The face-palm test (Bender, I952) or face-uppermost conducting segment test was 'normal' in seven of the $9 / 22$ group. In the two patients in which only the face stimulus was perceived at the first trial it reverted to 'normal' after the patient's attention was directed to the distal stimulus by abandoning synchronicity and by stimulating the distal area prior to the face. Once the patient had felt the distal stimulus, synchronous stimulation became 'normal'. This underscores how important synchronicity of stimulation is (Critchley, 1949) and may suggest that to some degree attention plays a role as well as dominance of the proximal over the distal stimulus. However, it could also be argued that the initial inattention may be based upon an ever so small perceptual reduction.

The phenomenon of extinction in patients in spinal cord trauma suggests a reduced perceptual input so that fewer impulses reach the cerebral cortex for interpretation. 'The cerebral cortex is the organ by which we are able to focus attention upon the changes evoked by sensory impulses' (Head and Holmes, I9I I, quoted by Critchley, 1949). Usually the area of extinction coincides with hypesthesia demonstrable by the ipsilateral single stimulus method. Thus extinction of spinal cord injury differs from that caused by cortical cerebral damage in that the former implies a relative paucity of receptors and the latter a reduction of processing and integrating structures. On the basis of experimental studies in monkeys, Eidelberg and Schwartz (I97I) have offered a hypothesis which explains the clinical findings of this report: 'Tactile extinction is caused by a reduced somatosensory input via one spinothalamic tract or by reduced functional mass in areas concerned with somatic sensation in one hemisphere relative to the other'. Similar thoughts have been expressed by Nathan (1946), by Bender and Furlow (1948) and by Critchley (1949).

\section{Synesthesia}

Critchley (1949) quotes Jones (1907) as the first to use the term synchiria, i.e., a unilateral stimulus to the unaffected side causes bilateral responses. This terminology was accepted by Bender (1945, 1952) who also called it synesthesia and by Eidelberg and Schwartz (I97I). Allesthesia or allochiria refers to the phenomenon of a contralateral response to a unilateral stimulus also delivered to the unaffected side. Synesthesialgia (Wechsler, 1943 quoted by Bender, I945) refers to a phenomenon observed in causalgia when a unilateral stimulus to the affected side causes a pain response in the unaffected side.

While undoubtedly other workers have noticed synesthesia in paraplegia I am not aware of reports to that effect.

I use the term synesthesia slightly modified but yet in accordance with Bender's 
(I952) concept, namely that one stimulus delivered to an area of normesthesia above the level of the cord lesion will elicit two sensations, one well localised and the other in ipsi- or bilateral anaesthetic parts of the body.

Six patients (five males and one female) presented the phenomenon of synesthesia (I2 per cent). The age of the patient did not seem to play a part (the five males' age ranged from 21 to 33 years, the female was 52 years old). The age of the lesion ranged from $I \frac{1}{2}$ years to Io years post-trauma (mean almost $5 \frac{1}{2}$ years). One of the patients (No. 3 ) injured 3 years ago noted the beginning of synesthesia $I \frac{1}{2}$ years after injury. Another patient (No. 2) whose injury was $\mathrm{I} \frac{1}{2}$ years old had occasional synesthesia which he could not elicit 'on command'. Synesthesia does not appear immediately after injury. Synesthesia did not correlate with the lesion's level and extent. Four patients had cervical and two had thoracic lesions. Four patients had upper and two had lower motor neuron signs; of the latter one patient had a complete upper motor neuron lesion below $\mathrm{C}_{5}$ but following phenolisation developed lower motor neuron signs. The other patient had a lower motor neuron lesion by virtue of his lumbar injury.

The stimuli of touch, pressure, vibration, scratching or rubbing the skin were delivered to normesthetic areas above the fractured vertebra. One patient responded to midline stimulation by pressure to the sternum (No. 3) with a sensation in the perineum. Five patients had ipsilateral (Nos. I to 5) and one patient (No. 6) had bilateral responses. Rubbing the skin of the back unilaterally between $\mathrm{T}_{4}$ and T6 elicited a 'deep' sensation in the ipsi- and contralateral leg which the patient 'liked'. Scratching and/or rubbing the skin elicited synesthesia in three of the six patients.

With the exception of one patient (No. 2) who could not elicit synesthesia on command, all other patients did so promptly when stimulated either by themselves or by the observer.

Four patients (Nos. 2 through 5) showed phenomena of extinction, two patients (Nos. I and 6) did not.

As easy as it is to obtain information on synesthesia simply by asking the patient, as difficult is it to explain this phenomenon. The following thoughts are hypothetical:

Synesthesia of the spinal cord patient differs from synchiria in monkeys (Eidelberg and Schwartz, I97I) in that bilaterality was found in only one (No. 6) of the six patients. Furthermore, in four of six patients extinction was present when it should have been absent because of its 'reciprocal relationship' with synchiria in the monkey (Eidelberg and Schwartz, I97I).

It was interesting that stimulation by scratching or rubbing the skin produced synesthesia in three of the six patients. That stimulus elicited 'causalgia' in patients with peripheral traumatic neuropathy which was alleviated by neurolysis (Bender, I945), i.e., removing an artificial synapse. An artificial synapse of the cord has been hypothetised as a source of extero- and proprioceptive phantom limb sensations in para- and tetraplegic patients (Bors, I95I and 1963).

Bender (1945) suggested two reflex arcs to be operant in causalgia: one in the cerebral cortex and the other in the spinal cord. The former explains why the sight or noise of scratching the skin, or the mere thought of it, produces the same response as the actual scratching. This means causalgia could be induced by activating the memory of the event and its effect on the body schema. That is a process reminding of the activation of motor phantom sensation in para- and tetraplegic patients by recalling their body images. Indeed, it was amazing that five patients (Nos. I, 3, 4, 5 and 6) had volitional phantom movements of toes and four had additional visceral 
phantom sensations of urination and/or defaecation. Only one patient (No. 2) whose synesthesia could not be elicted 'on command' had no movement phantoms of somatic or visceral structures.

Synesthesia of patients with spinal cord injury could be understood as the sensory counterpart of the motor phantom sensation; it is elicited by stimulating the normesthetic zone above the lesion; the sensory input consists of impulses of actual perception and additional impulses modulated by an artificial synapse at the end of the rostral cord stump.

\section{Summary}

Fifty patients with spinal cord injury were examined at random regarding phenomena of $(a)$ extinction and $(b)$ synesthesia.

(a). Testing for extinction was done with the method of simultaneous double stimulation; extinction was present in 20 (40 per cent) patients. No correlation was found between extinction and the following parameters: age of patient and duration of spinal cord injury, level and extent of the lesion or accompanying head injury. Modalities of superficial sensibility became extinct while deep sensibility (Pallesthesia, kinesthesia) did not. Extinction was more frequent with unilateral than with bilateral, symmetrical or asymmetrical double stimulation. Extinction in patients with spinal cord injury is probably caused by a reduction of the sensory input from zones of hypesthesia. Extinction indicates the longitudinal extension of a lesion.

(b). Synesthesia of patients with spinal cord injury is elicited by stimulating the normesthetic skin just above the lesion. In response two sensations are felt, one well localised, the other ipsi- or bilaterally in anaesthetic parts of the body. Synesthesia was observed in six ( 12 per cent) of the 50 patients. The stimuli consisted of touch, pressure, vibration, scratching or rubbing the skin; the latter two stimuli were efficient in three of the six patients. The responses were ipsilateral in five and bilateral in one patient. Neither the age of the patient and of the lesion, nor its level and extent seemed to correlate with the phenomenon. Four of the six patients had a co-existence of synesthesia and extinction, the remaining two patients had only synesthesia. Five of the six patients also had volitional phantom movements of the toes and four patients had additional visceral phantoms of micturition and defaecation. The findings are discussed. Synesthesia of spinal man seems to be a phantom sensation modulated by the sensory input from an artificial synapse of the cord located at the end of its rostral stump.

Acknowledgements. I wish to thank Drs John S. Young, David J. E. Cheshire and John $M$. Vivian for permission to examine their patients and to Miss Jeanne Stahl for preparing the manuscript.

\section{REFERENCES}

BeNDER, M. B. (1945). Extinction and precipitation of cutaneous sensations. Arch. Neurol. Psychiat. 54, I-9.

BENDER, M. B. (1948). The advantages of the method of simultaneous stimulation in the neurological examination. Med. Clin. N. Amer. 32, 755-758.

Bender, M. B. (1952). Disorders in Perception. Charles C. Thomas, Springfield, Ill.

BENDER, M. B. \& Furlow, L. T. (I948). Phenomenon of visual extinction in homonymous fields and psychological principles involved. Arch. Neurol. Psychiat. 53 29-33.

Bors, E. (I95I). Phantom limbs of patients with spinal cord injury. Arch. Neurol. Psychiat. 66, 610-631. 
Bors, E. (I963). Phantom limbs in patients with spinalcord injury. In P. Harris (ed.), Spinal Injuries, Proceedings of a Symposium, pp. I5-22. Royal College of Surgeons, Edinburgh.

Bors, E. (I964). Simple methods of examination in paraplegia. I. The spoon test. Paraplegia, 2, I7-I9.

CaLNE, D. B. \& Pallis, C. A. (I966). Vibratory sense: a critical review. Brain, 89, 723-746.

Critchley, M. (I949). The phenomonon of tactile inattention with special reference to parietal lesions. Brain, 72, 538-56r.

Critchley, M. (1953, 1966). The Parietal Lobes. Hafner Publishing Company, New York-London.

Dyck, P. J., Curtis, D. J., Bushek, W. \& Oxford, K. (I974). Description of 'Minnesota thermodisks' and normal values of thermo-discrimination. Neurology (Minneapolis), 24, 325-330.

EIDELBERG, E. \& SChWARTZ, A. S. (I97I). Experimental analysis of the extinction phenomenon in monkeys. Brain, 94, 9I-I08.

Gutrmann, L. (1976). Spinal Cord Injuries: Comprehensive Management and Research, 2nd Ed. Blackwell Scientific Publications, Oxford.

Nathan, P. W. (I946). On simultaneous bilateral stimulation of the body in a lesion of the parietal lobe. Brain, 69, 325-334.

Schwartz, A. S., Marchok, P. L. \& FlynN, R. E. (1977). A sensitive test for tactile extinction: Results in patients with parietal and frontal lobe disease. f. Neurol. Neurosurg. and Psychiat. 40, 228-233.

Wortis, S. B., BENDER, M. B. \& TeUBER, H. L. (I948). The significance of the phenomenon of extinction. F. Nerv. Ment. Dis. 107. 382-387. 